\title{
Atividade sérica de aspartato aminotransferase, creatina quinase, gama-glutamiltransferase, lactato desidrogenase e glicemia de cavalos da raça P.S.I. submetidos a exercícios de diferentes intensidades
}

\author{
Serum activities of aspartate aminotransferase, creatine kinase, \\ gamma glutamyltransferase, lactate dehydrogenase and glycaemia \\ in thoroughbred horses submitted to exercise of different intensities
}

\author{
Paula Spinha de Toledo, ${ }^{\star}$ Miguel Domingues Júnior, ${ }^{\star \star}$ Wilson Roberto Fernandes, ${ }^{\star \star \star}$ Maurício Magone, ${ }^{\star \star \star \star}$
}

\begin{abstract}
Resumo
No presente estudo foram colhidas, durante seis meses, amostras seriadas de sangue de 10 eqüinos da raça Puro Sangue Inglês (P.S.I) submetidos a exercícios de diferentes intensidades, a saber: exercício leve (caminhada), moderado (trote), e intenso (galope forte). A partir disso, foram mensurados os níveis séricos de aspartato aminotransferase (AST), creatina quinase (CK), gama-glutamiltransferase (GGT), lactato desidrogenase (LDH), e de glicose plasmática. Os resultados demonstraram que houve um aumento da concentração sérica da enzima creatina quinase (CK) após os exercícios moderado e intenso. Além disso, foi também observada uma elevação dos teores plasmáticos de glicose após os exercícios leve, moderado e forte. Por fim, com relação às enzimas séricas aspartato aminotransferase (AST), gama glutamiltransferase (GGT) e lactato desidrogenase (LDH), não foram observadas alterações em suas respectivas concentrações, antes e após a atividade física.
\end{abstract}

Palavras-chave: eqüinos; PSI; bioquímica sérica; tipo de exercício.

\begin{abstract}
In this study a series of blood samples were obtained from ten Thoroughbred horses submitted to exercises of different intensity, over a six-month period. Measurements were made of the levels of aspartate aminotransferase (AST), creatine kinase (CK), gamma glutamyltransferase (GGT), lactate dehydrogenase (LDH) and glucose in the serum. The results showed that there was an increase on serum concentration of creatine kinase (CK) after moderate and intense exercises. Furthermore, a rise was observed in the level of glucose in the plasma after light, moderate and strenuous exercises. In relation to aspartate aminotrasferase (AST), gamma glutamyltransferase (GGT) and lactate dehydrogenase (LDH), no alteration was found in the values before and after exercise.
\end{abstract}

Keywords: equine; Thoroughbred; biochemical parameters; exercise type.

\section{Introdução}

O conhecimento dos valores fisiológicos das concentrações das diferentes substâncias presentes no soro sangüíneo, usados para a avaliação das funções de órgãos, dentre os quais destacam-se o fígado e rim, permite verificar-se alterações que nos auxiliam no diagnóstico e prognóstico de muitos processos patológicos que acometem os animais do- mésticos. Autores clássicos de estudos na área de patologia clínica veterinária (Braun, 1946; Vogel, 1957; Birgel, 1967 e Ferreira Neto et al. , 1982) são unânimes em ressaltar a importância dos valores padrões de referência para a adequada interpretação dos resultados de exames bioquímicos no soro sangüíneo de diferentes espécies animais. De grande

\footnotetext{
* Aluna da graduação da FMVZ - USP e bolsista CNPq. Avenida Prof. Dr. Orlando Marques de Paiva, 87 - Cidade Universitária - CEP 05508-900 São Paulo, SP. Tels.: (11) 3818-4246 / (11)3818-4240 - E-mail.paulaspinha @yahoo.com

** Aluno da graduação da FMVZ - USP e bolsista FAPESP.

*** Professor Doutor do Departamento de Clínica Médica da FMVZ - USP.

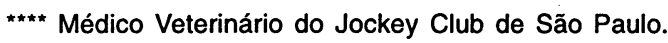


valia, também, é o conhecimento das alterações da bioquímica sérica, que surgem, por exemplo, em decorrência do esforço físico. Apesar da importância, nota-se escassez de literatura nacional sobre este assunto, sendo poucos e muito específicos os trabalhos descritos.

Tendo em vista esta lacuna presente em estudos sobre a resposta sangüínea ao exercício em cavalos submetidos a corrida no Brasil, o presente trabalho almeja contribuir para a pesquisa dos índices séricos de aspartato aminotransferase (AST), creatina quinase (CK), gama-glutamiltransferase (GGT) e glicose, em animais sob a influência de treinamento e/ou destinados a provas de velocidade no estado de São Paulo.

\section{Revisão de literatura}

Como os resultados obtidos pelo eletrocardiograma, por exames hematimétricos ou pela determinação de enzimas séricas não explicavam de forma convincente as variações de performance, tornou-se necessária a intensificação das pesquisas sobre este assunto, optando-se pela avaliação de outros parâmetros bioquímicos do sangue que pudessem influir no rendimento dos eqüinos de competição.

Nesse sentido, Thompson (1962), estudando a correlação entre os níveis plasmáticos de algumas enzimas e a integridade da fibra muscular, afirmou que $o$ aumento do nível sérico de enzimas como a creatina quinase $(\mathrm{CK})$ e a lactato desidrogenase (LDH) estava associado ao aumento da permeabilidade da membrana ou à destruição da fibra muscular. Cardinet et al. (1963) demonstraram existir correlação positiva entre o aumento sérico de creatina quinase e a ocorrência de tying up, uma síndrome semelhante à azotúria ou mioglobinúria pós-exercício.

Aitken et al. (1974), estudando as variações de CK no sangue de eqüinos $\mathrm{PSI}$ e em eqüinos de tração, submetidos a 30 minutos de exercício físico, concluíram que os níveis séricos de CK não foram parâmetros sensíveis para evidenciar o preparo físico desses animais, pois as alterações mais evidentes apareceram após cinco a seis horas do início da atividade física.

Em 1975, Blackmore e Elton, avaliando as enzimas aspartato aminotransferase (AST) e creatina quinase (CK) em potros e em animais adultos em repouso e em treinamento, observaram aumento nos níveis séricos destas enzimas durante o treinamento e concluíram que ambas eram de origem muscular, esquelética ou cardíaca. Observação semelhante foi feita por Rose et al. (1979), que mensurou as mesmas ezimas em potros neonatos. Com relação à glicose, estes mesmos autores observaram elevação progressiva dos níveis glicêmicos de acordo com a faixa etária.

Analisando a amostra de sangue de 12 potros sadios, com idade entre duas e oito semanas, de 60 éguas sadias da raça PSI com idade variada, e de 50 cavalos de passeio em treinamento, Lumsden et al. (1980) observaram uma maior concentração sérica de LDH e CK nos potros seguidos pelas éguas e em menor concentração nos animais em treinamento. Com relação à AST, observou-se o inverso, ou seja, os menores valores são observados nos potros e os maiores em animais em treinamento.

$\mathrm{Na}$ França, Braun et al. (1982) verificaram que os valores médios de gama-glutamiltransferase (GGT) em cavalos de corri- das (galope ou trote) foram significantemente maiores que os de outras categorias, e que nos machos as taxas de atividade da enzima foram menores que aqueles das fêmeas e dos animais castrados.

Em 1983, Rose et al. voltaram a estudar o efeito do treinamento sobre alguns constituintes bioquímicos de sangue de eqüinos, padronizando, para os quatro animais utilizados no experimento, o mesmo tipo de exercício durante sete semanas, observando que houve pouca variação de glicose, bem como de potássio, creatinina, AST, GGT, sendo a uréia o único elemento que apresentou aumento absoluto, a partir da quinta semana de tratamento.

No Brasil, em 1986, a atividade sérica da enzima CK em animais PSI e Mangalarga marchador foram estudados por Maitin et al., que observaram níveis séricos mais elevados desta enzima nos Mangalarga do que nos PSI, sendo que estes níveis independeram da faixa etária. No entanto, em trabalho realizado por Sommer et al. (1988), foram encontrados valores mais elevados de AST para os potros do que para as demais categorias de animais avaliadas.

Fernandes (1994), em São Paulo, através de exames clínicos e laboratoriais, pesquisou os efeitos da prova de enduro em 45 eqüinos sadios de duas raças puras e mestiços, com idades entre quatro e dez anos, demonstrando não haver variação significante nos níveis de AST e GGT decorrentes do exercício físico.

\section{Material e métodos}

\section{Animais}

Foram utilizados dez animais da raça Puro-Sangue Inglês, cinco machos e cinco fêmeas, com idade variando entre três e quatro anos, que estavam em treinamento para participar de provas de turfe no Jockey Club de São Paulo, tanto em pista de areia como de grama, com distâncias variando de 1.000 a 1.600 metros.

\section{Colheita das amostras}

As amostras de sangue nestes animais foram colhidas em dois tempos, sendo $T 1$, antes do exercício do treinamento e T2, trinta minutos após o exercício. Estas amostras foram acondicionadas em diferentes frascos de Vacutainerò, sendo um com fluoreto de sódio, para a quantificação de glicose, e outro sem anticoagulante, para as demais mensurações.

Estas colheitas foram feitas semanalmente, durante seis meses, período no qual os animais foram submetidos a treinamento de diferentes intensidades, a saber: exercício leve (caminhada), moderado (trote) e intenso (galope forte), totalizando 346 amostras, das quais 173 foram colhidas antes do esforço físico e 173, após o mesmo.

A partir destas amostras, foram feitas as dosagens de glicose, lactato desidrogenase, creatina quinase, aspartato aminotransferase e gama-glutamiltransferase, segundo técnicas preconizadas em Schimid e vonFostner (1986).

Os resultados obtidos ao final de seis meses foram avaliados estatisticamente com o auxílio do pacote estatístico Statistic Instat do Centro de Computação Eletrônica da Universidade de São Paulo, a fim de se estabelecer as possíveis 
alterações nos valores da bioquímica sérica, em decorrência do esforço físico proporcionado pelos tipos de exercício.

\section{Resultados}

Os resultados a seguir referem-se às amostras colhidas durante os seis meses de experimento, com totalidade de 22 dias de colheita.

Tabela 1 - Médias e os respectivos desvios-padrão dos parâmetros bioquímicos avaliados nos eqüinos da raça Puro-Sangue Inglês, antes e após os diferentes tipos de exercício e independentemente da sua intensidade, no decorrer do período de observação. São Paulo, 1999

\begin{tabular}{|c|c|c|c|c|c|}
\hline PARÂMETROS & & $\begin{array}{c}\text { EXERCÍCIO } \\
\text { LEVE } \\
(n=39) \\
\end{array}$ & $\begin{array}{c}\text { EXERCÍCIO } \\
\text { MODERADO } \\
(n=94)\end{array}$ & $\begin{array}{c}\text { EXERCÍCIO } \\
\text { INTENSO } \\
(\mathrm{n}=40)\end{array}$ & $\begin{array}{l}\text { INDEPENDENTTE } \\
\text { DO EXERCICIO } \\
(n=173)\end{array}$ \\
\hline $\begin{array}{l}\text { AST } \\
\text { (URL) }\end{array}$ & $\begin{array}{l}\text { Antes } \\
\text { Depois }\end{array}$ & $\begin{array}{l}212,7 \pm 118,6^{A} \\
211,6 \pm 110,8^{A}\end{array}$ & $\begin{array}{l}215,2 \pm 117,3^{A} \\
221,3 \pm 113,6^{A}\end{array}$ & $\begin{array}{l}178,9 \pm 59,4^{A} \\
182,1 \pm 53,3^{A}\end{array}$ & $\begin{array}{l}206,2 \pm 107,5 \\
210,1 \pm 103,0\end{array}$ \\
\hline $\begin{array}{l}\text { GGT } \\
(\text { (UL) }\end{array}$ & $\begin{array}{l}\text { Antes } \\
\text { Depois }\end{array}$ & $\begin{array}{l}13,8 \pm 4,9^{\mathrm{B}} \\
13,6 \pm 5,2^{\mathrm{B}}\end{array}$ & $\begin{array}{l}13,0 \pm 4,7^{8} \\
13,3 \pm 5,0^{B}\end{array}$ & $\begin{array}{l}11,5 \pm 4,2^{\mathrm{B}} \\
11,6 \pm 4,5^{\mathrm{B}}\end{array}$ & $\begin{array}{l}12,8 \pm 4,6 \\
12,9 \pm 5,0\end{array}$ \\
\hline $\begin{array}{l}\text { CK } \\
\text { (ULL) }\end{array}$ & $\begin{array}{l}\text { Antes } \\
\text { Depois }\end{array}$ & $\begin{array}{l}81,3 \pm 44,6^{c} \\
65,3 \pm 21,4\end{array}$ & $\begin{array}{c}81,0 \pm 48,1^{\mathrm{C}} \\
114,3 \pm 107,1^{D}\end{array}$ & $\begin{array}{l}66,5 \pm 16,3^{c} \\
91,8 \pm 36,7^{D}\end{array}$ & $\begin{array}{l}77,9 \pm 42,3 \\
98,1 \pm 83,7\end{array}$ \\
\hline $\begin{array}{l}\text { LDH } \\
\text { (ULL) }\end{array}$ & $\begin{array}{l}\text { Antes } \\
\text { Depois }\end{array}$ & $\begin{array}{l}190,9 \pm 56,6^{\mathrm{E}} \\
161,6 \pm 40,2^{\mathrm{E}}\end{array}$ & $\begin{array}{l}188,2 \pm 58,7^{\mathrm{E}} \\
171,7 \pm 56,4\end{array}$ & $\begin{array}{l}167,4 \pm 49,4 \mathrm{E} \\
169,7 \pm 34,0 \mathrm{E}\end{array}$ & $\begin{array}{l}184,0 \pm 56,6 \\
168,8 \pm 48,2\end{array}$ \\
\hline GLICOSE (mg/dl) & $\begin{array}{c}\text { Antes } \\
\text { Depois }\end{array}$ & $\begin{array}{c}94,3 \pm 6,8^{F} \\
102,6 \pm 12,3^{G}\end{array}$ & $\begin{array}{c}94,8 \pm 7,7^{F} \\
102,9 \pm 11,2^{G}\end{array}$ & $\begin{array}{c}95,9 \pm 6,4^{F} \\
113,8 \pm 12,3^{G}\end{array}$ & $\begin{array}{c}94,9 \pm 7,2 \\
105,3 \pm 12,5\end{array}$ \\
\hline
\end{tabular}

(n) = número de amostras utilizadas.

OBS: Letras diferentes no mesmo parâmetro da tabela indicam diferenças estatisticamente significantes ao nível de $p<0,05$.

\section{Discussão dos resultados}

No presente trabalho pôde-se observar um aumento significante dos valores de CK após os exercícios moderado e intenso, quando comparados ao repouso e ao exercício leve.

A elevação dos níveis plasmáticos de CK tem sido um achado consistente em cavalos submetidos a exercícios. Assim, Keenan (1979), trabalhando com animais de corrida, observou um aumento estatisticamente significante dos valores de CK após o exercício. Rose et al. (1980a), por sua vez, relataram um aumento das concentrações de CK e AST em cavalos na etapa de resistência da chamada prova de três dias. Da mesma forma, Snow et al. (1982), trabalhando com animais de corrida submetidos a exercícios prolongados, constataram aumento significante da concentração desta enzima, não estando este aumento relacionado ao grau de fadiga do animal.

Tais resultados, por outro lado, diferem das afirmações de Milne et al. (1976), Oosterbaan et al. (1991) e Fernandes (1994), que não encontraram diferenças estatisticamente significantes entre os teores séricos médios de CK após o exercício.

As atividades das enzimas aspartato aminotransferase (AST) e creatina quinase (CK), encontradas primariamente na musculatura esquelética, podem estar associadas à destruição de fibras musculares (Lindholm, 1987; Noakes, 1987). Em cavalos após exercício de diferentes intensidades, são ob- servados aumentos na atividade destas enzimas. Muitas vezes, estes aumentos não estão associados aos sinais clínicos de miopatia (Cardinet et al., 1963). Nesse sentido, Anderson (1975) sugeriu que a elevação pós-exercício das enzimas musculares no soro de cavalos não resultaram de necrose da célula muscular, e sim de uma mudança na permeabilidade da membrana celular. Milne et al. (1976), por sua vez, atribuíram este aumento de permeabilidade celular à hipóxia, de forma que cavalos não condicionados para o exercício apresentavam uma maior alteração da concentração de CK sérica, quando comparados aos animais treinados. Assim, a resposta enzimática frente a um determinado exercício poderia ser usada como estimativa bioquímica da aptidão física. $\mathrm{O}$ aumento dos níveis séricos desta enzima, sem o aparecimento de sinais clínicos de dano muscular, foi, também, atribuído à diminuição do clearance do CK do plasma pelo fígado (Harris, 1988). De fato, Volfinger et al. (1994) calcularam a quantidade de fibras musculares lesionadas em cavalos, baseado na liberação de CK da musculatura esquelética, e concluíram que somente altos níveis plasmáticos de CK refletiriam miólise significante.

Por fim, vale ressaltar que estudos realizados por Anderson (1975) sugerem que o aumento de CK está inversamente relacionado à aptidão ao exercício e diretamente relacionado à sua duração.

No presente trabalho, pôde-se observar que, apesar de haver variações entre os valores de AST antes e depois dos diferentes exercícios e entre os trabalhos de diferentes intensidades, tais alterações não foram estatisticamente significantes. Estes resultados estão de acordo com os estudos realizados por Snow et al. (1982), que trabalharam com eqüinos submetidos à prova de enduro de 80 quilômetros, e por Rose et al. (1983), com animais de cross-country. Somente Rose et al. (1980b) e Snow (1990) afirmaram que as alterações na atividade de aspartato aminotransferase foram estatisticamente significantes ao estudarem animais submetidos às chamadas provas dos três dias, onde a exigência física é mais intensa.

Os resultados da avaliação da concentração sérica de GGT demonstraram não haver diferenças estatisticamente significantes entre os valores obtidos antes e após os exercicios. Da mesma forma, os valores obtidos após os diferentes tipos de trabalho não foram estatisticamente diferentes.

Os resulltados obtidos no presente experimento estão de acordo com aqueles encontrados por Blackmore et al. (1979), estudando cavalos de corrida submetidos a esforço físico, por Rose e Hodgson (1982), analisando cavalos de enduro em treinamento, e por Fernandes (1994), trabalhando com animais submetidos a provas de enduro.

Rose et al. (1983), pesquisando cavalos de passeio submetidos a exercício submáximo em esteira, encontraram eleva- 
ção significante dos valores desta enzima associado ao treinamento, embora não tenham sido observadas diferenças estatisticamente significantes nos valores obtidos antes e depois do exercício.

A gama glutamiltransferase é uma enzima de membranas celulares que desempenha função importante, principalmente ao nível renal, na reabsorção de aminoácidos a partir do filtrado glomerular, e, em menor escala, na reabsorção de aminoácidos do lúmen intestinal. Apesar de sua atividade mais intensa no tecido renal, o aumento sérico da GGT geralmente é indicativo de lesão hepática, pois é a primeira enzima a ter seus níveis séricos aumentados quando ocorrem alterações no fígado. Tal fato permite que se considere a dosagem de GGT importante para melhor avaliação de AST, que se supõe ser de origem muscular.

Os valores séricos de lactato desidrogenase, obtidos antes e após o exercício, não apresentaram diferenças estatisticamente significantes. Da mesma forma, as comparações entre os diferentes tipos de exercício também não mostraram alterações significantes.

Os resultados obtidos no presente experimento estão de acordo com aqueles referidos nos trabalhos de Aitken et al. (1974), Milne et al. (1976) e Fernandes (1994), que demonstraram que o aumento da atividade de LDH, após o exercício, não foi estatisticamente significante.

Com relação à glicose plasmática, observou-se um aumento de sua concentração após exercício, independentemente da intensidade deste. Ao se comparar os valores de glicose obtidos após os diversos tipos de exercícios, constatou-se que estes foram mais expressivos após o exercício forte, se comparados aos obtidos pós-exercícios leve e moderado. Este aumento, qualquer que seja a intensidade, indica que a mobilização da glicose excedeu a sua utilização pela musculatura, sendo provável resultado da combinação dos aumentos da atividade simpática e da concentração de glucagon plasmático (Lucke e Hall, 1980a,b) e da diminuição na concentração de insulina circulante (Lucke e Hall, 1980a,b; Snow e Rose, 1981). O aumento da concentração

\section{Referências}

AITKEN, C. A. O., AKINRINMADE, J. F., FAJIMI, J. L. Haematological and serum biochemical parameters used to asses fitness in the horse. Joumal of South African Veterinary Association, v. 45, n. 4, p. 361-379, 1974.

AITKEN, M. M., ANDERSON, M. G., MACKENZIE, G., et al. Correlations between Physiological and Biochemical Parameters used to asses fitness in the horse. Joumal of the South African Veterinary Association, v. 45, n. 4, p. 361-370, 1974.

ANDERSON, M. G. The influence of exercise on serum enzyme levels in the horse. Equine Veterinary Journal, v. 7, n. 3, p. 160-165, 1975.

BAUER, J. E., ASQUITH, R. L., KIVIPELTO, J. Serum biochemical indicators of liver function in neonatal foals. American Journal of Veterinary Research, v. 50, n. 12, p. 2037-2041, 1989.

BIRGEL, E. H. Contribuição à hematologia de caprinos (Capra hircus) criados no Estado de São Paulo. Determinação dos teores de proteinas séricas e plasmática em cabras normais. Influência de fatores raciais, alimentares e etários. São Paulo, 1967. 37 p. Dissertação (Mestrado). Faculdade de Medicina Veterinária e Zootecnia da Universidade de São Paulo. sérica da glicose foi também observado nos cavalos em competições de resistência, como as chamadas provas de três dias (Rose et al., 1980b). Por outro lado, Lucke e Hall (1978), Snow et al. (1982) e Fernandes (1994) relataram uma redução dos níveis séricos de glicose após a prova de enduro, seguido de aumento de glicemia durante o repouso. Ressaltam-se, ainda, os estudos de Snow et al. (1982) e Oosterbaan et al. (1991) que avaliaram a glicemia em amostras de soro colhidas durante a realização da prova de enduro, nos quais verificaram que a curva glicêmica apresentava elevação até a metade da prova para depois demonstrar declínio, atingindo, ao final do esforço físico, os níveis mínimos de glicose sangüínea.

Lindholm et al. (1974), em seus estudos, mostraram uma baixa depleção de glicogênio em cavalos puro-sangue submetidos a corridas de curta distância. Essas diferenças podem estar relacionadas à grande habilidade do cavalo em utilizar ácidos graxos livres antes do glicogênio, refletindo um melhor treinamento ou uma diferença entre as raças estudadas.

\section{Conclusões}

A análise dos resultados obtidos permitem as seguintes conclusões:

- Não foram observadas alterações nas concentrações das enzimas séricas aspartato aminotransferase (AST), gamaglutamiltransferase (GGT) e lactato desidrogenase (LDH), antes e após os exercícios, qualquer que seja sua intensidade;

- A concentração sérica da enzima creatina quinase (CK) sofreu aumento após os exercícios moderado e intenso, sendo os valores obtidos maiores que aqueles encontrados após trabalho leve;

- Os valores médios dos teores séricos de glicose sofreram elevação nos três tipos de exercício, sendo proporcional à intensidade do esforço físico, apesar do fato não ter significância estatística.

BLACKMORE, D. J., WILLET, K., AGNESS, D. Selenium and Gammaglutamyl transferase activity in the serum of Thoroughbred. Research in Veterinary Science, v. 26, p. 7-80, 1979.

BRAUN, J. P., BARDIES, J., THOUVENOT, J. P., BERNARD, P., RICO, A. G. Serum gamma-glutamyltransferase in equids: Reference physiologic values. American Journal Veterinary Research, v. 43, n. 2, p. 339340,1982

BRAUN, W. Average levels of various constituents, physical properties, and formed elements of the blood of cows on pasture. American Journal of Veterinary Research, v. 7, n. 25, p. 450-454, 1946.

CARDINET, G. H.; FOWLER, M. E.; TYLER, W. S. The effects of training, exercise and tying-up on serum transaminase activities in the horse. American Journal of Veterinary Research, v. 24, p. 980-985, 1963.

FERNANDES, W. R. Alterações dos Parâmetros do Eletrocardiograma e da Crase Sangüínea em Eqüinos das Raças Árabe e Mangalarga, bem como de Mestiços, submetidos à Prova de Enduro. São Paulo, 1994. 73 p. Dissertação (Doutorado). Faculdade de Medicina Veterinária e Zootecnia da Universidade de São Paulo.

FERREIRA NETO, J. M., VIANA, E. S., MAGALHÃES, M. M. Patologia Clínica Veterinária, Belo Horizonte: Rabelo e Brasil, 1982. 
HARRIS, P. A. Some aspects of the equine Rhabdomyolysis Syndrome. Inglaterra, 1988. Dissertação (Pós-Doutorado) da Universidade de Cambridge.

KEENAN, D. M. Changes of blood metabolites in horses after racing, with particular reference to uric acid. Australian Veterinary Journal, v. 55, n. 2, p. 54-57, 1979.

LINDHOLM, A. Pathophysiology of exercise induced diseases of the musculoskeletal system of the eqüine athlete. In: Eqüine Exercise Physiology 2. J. R. Gillespie and N. E. Robinson - ICEEP Publications: Davis, Califórnia, p. 711-727, 1987.

LINDHOLM, A., SALTIN, B. The Physiological and Biochemical Response of Standardbred Horses to Exercise of Varying Speed and Duration. Acta Veterinaria Scandinavia, v. 15, n. 3, p. 310-324, 1974.

LUCKE, J. N., HALL, G. M. Biochemical changes in horses during a 50 mile endurance ride. The Veterinary Record, v. 102, n. 16, p. 356-358, 1978.

LUCKE, J. N., HALL, G. M. Long distance exercise in horses: Golden Horseshoe Ride 1078. The Veterinary Record, v. 106, n. 18, p.405407, 1980a.

LUCKE, J. N., HALL, G. N. Further studies on the metabolic effects of long distance riding: Golden Horseshoe Ride 1979. Equine Veterinary Journal, v. 12, n. 4, p. 189-192, 1980 b.

LUMSDEN, J. H.; ROWE, R.; MULLEN, K. Haematology and biochemistry reference values for the lith horse. Canadian Journal of Comparative Medicine, v. 44, n. 1, p. 32-42, 1980.

MAITIN, R. E. C., COELHO, H. E., SOUZA, R. Níveis séricos de creatinaFosfoquinase (CPK) de eqüinos puro sangue e Mangalarga Marchador. Arquivo Brasileiro de Medicina Veterinária e Zootecnia, v. 38, n. 5, p. 657-663, 1986.

MILNE, D. W., SKARDA, R. T., GABEL, A. A.; et al. Effects of Training on Biochemical Values in Standardbred Horses. American Journal of Vterinary Research, v. 37, n. 3, p. 285-290, 1976.

NOAKES, T. D. Effect of exercise on serum enzyme activities in humans. Sport Medicine, v. 4, p. 245-267, 1987.

OOSTERBAAN, M. M. S. O., WENSING, T., BARNEVELD, ${ }^{\mathrm{a}}$ et al. Heart rate, Blood Biochemistry and Performance of Horses Competing in a $100 \mathrm{~km}$ endurance ride. The Veterinary Record, v. 128, n. 7, p. 175-179, 1991.

ROSE, J. R., ARNOLD, K. S., CHURCH, S., PARIS, R. Plasma and sweat eletrolyte concentrations in the horse during long distance exercise. Equine Veterinary Journal, v. 12, n. 1, p. 19-22, $1980^{\circ}$
ROSE, R. J., BACKHOUSE, J. W., ILKIW, J. E. Electrocardiography and haematology of horses competing in a three-day event. Australian Veterinary Journal, v. 56, n. 7, p. 318-320, 1980 b.

ROSE, R. J.;BACKHOUSE, W.; CHAN, W. Plasma biochemistry changes in thoroughbred foals during the first 4 weeks of life. Journal of Reproduction and Fertility, Supplement, v. 27, p. 601-605, 1979.

ROSE, R. J., HODGSON, D. R. Haematological and plasma biochemical parameters in endurance horses during training. Equine Veterinary Journal, v. 14, n. 2, p. 144-148, 1982.

ROSE, R. J.; HODGSON, D. R.; STEWART, J. H. Responses to submaximal treadmill exercise and training in the horse: changes in hematology, arterial blood gas and acid measurements plasma biochemical values and heart rate. The Veterinary Record, v. 113, $n$. 27, p. 612-618, 1983.

SCHIMID, M., von FOSTNER, L. A. Laboratorie testing in veterinary medicine diagnosis in the clinical monitoring. Mannheim: Boehringer, 1986, 253p.

SNOW, D. H. Haematological, Biochemical and Physiological changes in Horses and Ponies during the cross country stage of driving trial competitions. The Veterinary Record, v. 126, p. 233-239, 1990.

SNOW, D. H., KERR, M. G., NIMMO, M.; et al. Alterations in blood, sweat, urine and muscle composition during prolonged exercise in the horse. The Veterinary Record, v. 110, n. 16, p. 377-384, 1982.

SNOW, D. H., ROSE, R. J. Hormonal changes associated with long distance exercise. Equine Veterinary Journal, v. 13, n. 3, 195-197, 1981.

SOMMER, H., STYRIE, J., LINDNER, A. Blood plasma concentration of varius parameters in horses of different breeds of thoroughbreds with diffferent uses. In: Blackmore, D. J. Animal clinical biochemistrythe future. Cambridge University Press, 1988, p. 383-386.

THOMSON, W. H. Sources of error in the biochemical diagnosis of muscular dystrophy. Journal Neurologycal Neurosurgery Psychiatry, v. 25, p. 191-196, 1962.

VOGEL, J., RUSSO, E., SZECHY, A. M. Contribuição a bioquímica do sangue de zebus (Bos indicus) das raças Nelore e Guzerá. Revista Militar de Remonta e Veterinária, v. 17, n. 1-4, p. 47-55, 1957.

VOLFINGER, L., LASSOURD, V., MICHAUZ, J. M.; et al. Kinetic evaluation of muscle damage during exercise by calculation of amount of creatine kinase released. American Journal of Physiology, v. 266, p. R434 R441, 1994. 